\title{
Sensing of Gaseous Malodors in Landfills and Waste Treatment Plants
}

\author{
B. Fabbri ${ }^{*^{1}}$, S. Gherardi ${ }^{1}$, A. Gibertit ${ }^{1,2}$, V. Guidi ${ }^{1,2,3}$, C. Malagù ${ }^{1,3}$ \\ 1 Department of Physics and Earth Science, University of Ferrara, \\ Via Saragat 1/c, 44122 Ferrara, Italy, \\ ${ }^{2}$ MIST E-R S.C.R.L., Via P. Gobetti 101, 40129 Bologna, Italy \\ 3 IDASC - Istituto di Acustica e Sensoristica "O. M. Corbino," Italy \\ * Corresponding author. Tel. +390532 974213 \\ E-mail address: bfabbri@fe.infn.it
}

\begin{abstract}
:
We approached the problem of sensing gaseous pollutants and malodors originated from decomposition of organic compounds via chemoresistive gas sensors. A sensor array based on screen-printed films of mixed tin and titanium oxides, mixed tungsten and tin oxides, and zinc oxide has been tested on the main gaseous components of these malodors. N-butanol was also considered as a reference gas in the olfactometric intensity scale. Under proper working conditions the films can sensitively detect such gases either in dry or in wet environments, within the range of concentrations of interest for their monitoring. The array proved to be robust under solicitation by harmful interference gases such as $\mathrm{CO}, \mathrm{C}_{6} \mathrm{H}_{6}$ e $\mathrm{NO}_{2}$.
\end{abstract}

Key words: gas sensor, landfill, odor, sensor array, solid solution.

\section{Introduction}

Pollutants and malodors often accompany decomposition processes, giving rise to serious health risks and/or discomfort to the human agglomerates neighboring the plants where such gases are generated. Landfills and waste treatment plants are typical cases in which several types of emission gases or vapors must be carefully taken into account. In particular, landfill emissions are characterized by a very complex composition, while plants such as incinerators are potential sources of some kinds of pollutants, deriving from waste combustion, such as carbon monoxide and nitrogen oxides.

The study of the decomposition and waste combustion gases is of interest in several applications and a preliminary investigation to monitor landfill gas emission was performed in Ref. [1-6]. However, lack of selectivity is an issue and for that special care is needed while selecting the sensing units. Among the wide variety of decomposition gases we targeted ammonia, ethyl-mercaptan and sulphydric acid, because they are tracers of decomposition with stinging odor to our nose even down to very low concentrations.

Since the odorimetric aspect of the application is highly relevant, we also took into account the responses of all the selected sensors to $n$ butanol, because this latter is the reference gas the odorimetric intensity scale, useful to fix the threshold for the human perception of an odor [7]. In this work, we addressed the problem of detecting typical gaseous products of waste storage, by means of gas sensors based on thick-films of metal oxides and mixed solid solutions of them, taking into account also the possible interference of typical combustion products. In order to investigate these problems different measurements were carried out: tests to identify the best detecting temperature for each type of sensing, the response to an increasing concentration and the possible interference with gases such as $\mathrm{CO}, \mathrm{C}_{6} \mathrm{H}_{6}$ and $\mathrm{NO}_{2}$.

\section{Experimental}

\section{a. Selection of the sensors and preliminary operations}

A set of four metal-oxide semiconducting films has been selected for the purpose. The materials chosen are $\mathrm{ZnO}$, two solid solutions of $\mathrm{SnO}_{2}$ and $\mathrm{TiO}_{2}$, in proportions of $30 \%-70 \%$ 
respectively (named ST30), and 90\% - 10\% respectively (named ST90), and a solid solution of $\mathrm{WO}_{3}$ and $\mathrm{SnO}_{2}$ in proportions of $30 \%-70 \%$ respectively (named WS30). The details of powders synthesis are reported in Ref. [8-13].

Measurements were performed with the flowthrough technique in a sealed test chamber. Air and target gases were supplied by certified bottles, humidity was provided by means of a bubbler filled with distilled water. The gases chosen for gaseous malodors application are ethyl-mercaptan, ammonia, hydrogen sulfide and n-butanol as a reference gas for the odorimetric intensity, while $\mathrm{CO}, \mathrm{C}_{6} \mathrm{H}_{6}$ and $\mathrm{NO}_{2}$ were probed as combustion interferents. Humidity was monitored through a $\mathrm{HIH}-3610$ Series Honeywell sensor. We investigated the responses of the sensors under dry $(\mathrm{RH}<2 \%$ at $\left.35^{\circ} \mathrm{C}\right)$ and wet $\left(\mathrm{RH}=23 \%\right.$ at $\left.35^{\circ} \mathrm{C}\right)$ conditions.

\section{b. Response to decomposition gases}

The response of the set of sensors defined as $\left(G_{\text {gas }}-G_{\text {air }}\right) / G_{\text {air }}$, where $G_{\text {gas }}$ and $G_{\text {air }}$ are the conductance values in gas and in air, respectively. was investigated vs. working temperature in order to determine the optimal detecting condition for ethyl-mercaptan, ammonia, hydrogen sulfide. The concentrations of the target gases were chosen in order to be comparable with the Recommended Exposure Limits (REL) by NIOSH (United States National Institute for Occupational Safety and Health). Indeed, for ethyl-mercaptan we chose the REL concentration of $0.5 \mathrm{ppm}, 10 \mathrm{ppm}$ for ammonia $(\mathrm{REL}=25 \mathrm{ppm}), 2 \mathrm{ppm}$ for hydrogen sulfide $(\mathrm{REL}=10 \mathrm{ppm})$.

The experimental results show diversification in the responses to the three gases. This is an indication of suitability of this set of sensors for the selective detection of the three target gases. The optimal working temperature for each gas is reported in Tab. 1.

\begin{tabular}{|c|c|c|c|}
\hline Sensor & $\begin{array}{c}\text { ETHYL } \\
\text { MERCAPTAN } \\
0.5 p p m ~\left[{ }^{\circ} \mathbf{C}\right]\end{array}$ & $\begin{array}{c}\text { AMMONIA } \\
10 \mathrm{ppm}\left[{ }^{\circ} \mathbf{C}\right]\end{array}$ & $\begin{array}{c}\mathrm{H}_{2} \mathbf{S} \\
2 \mathrm{ppm} \\
{\left[{ }^{\circ} \mathbf{C}\right]}\end{array}$ \\
\hline ST30 & 500 & 600 & 550 \\
\hline ST90 & 500 & 550 & 550 \\
\hline WS30 & 400 & 550 & 400 \\
\hline ZnO & 400 & 400 & 400 \\
\hline
\end{tabular}

Tab. 1: The optimal working temperature Tbest for all analysed films.
At the best temperature for each gas, we measured the response to an incresing concentration of interest, highlighted in Figs. 13.

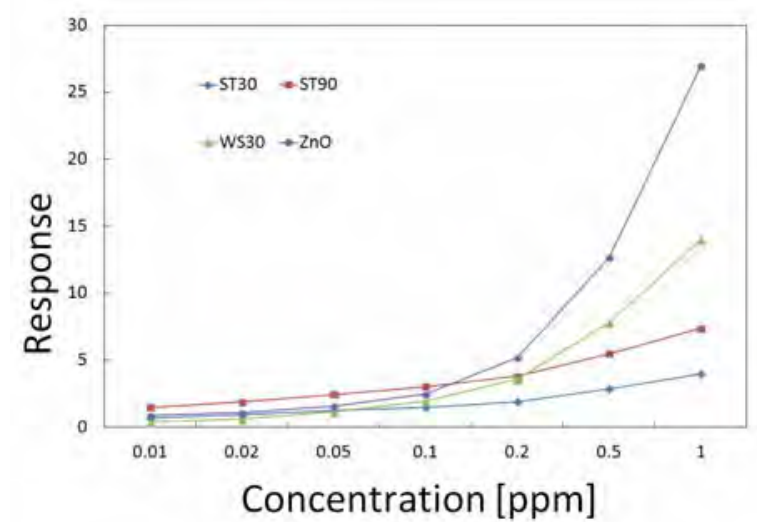

Fig. 1. Responses vs. ethyl-mercaptan within 0.01 and $1 \mathrm{ppm}$ dispersed in a dry carrier.

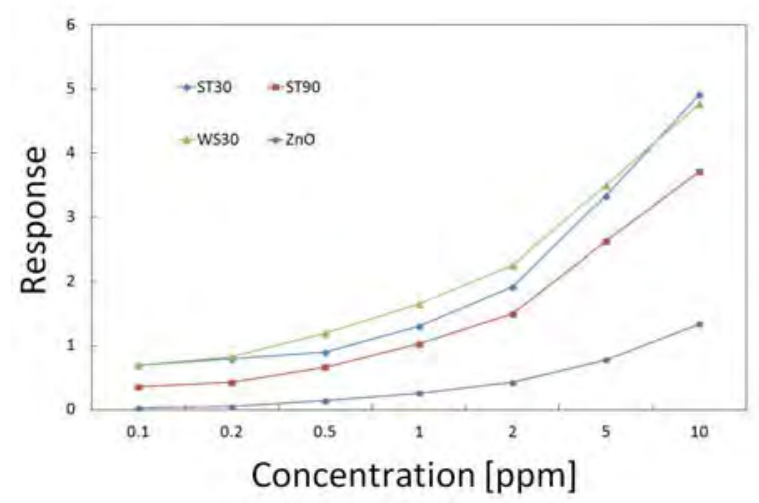

Fig. 2. Responses vs. ammonia within 0.1 and 10 ppm dispersed in a dry carrier.

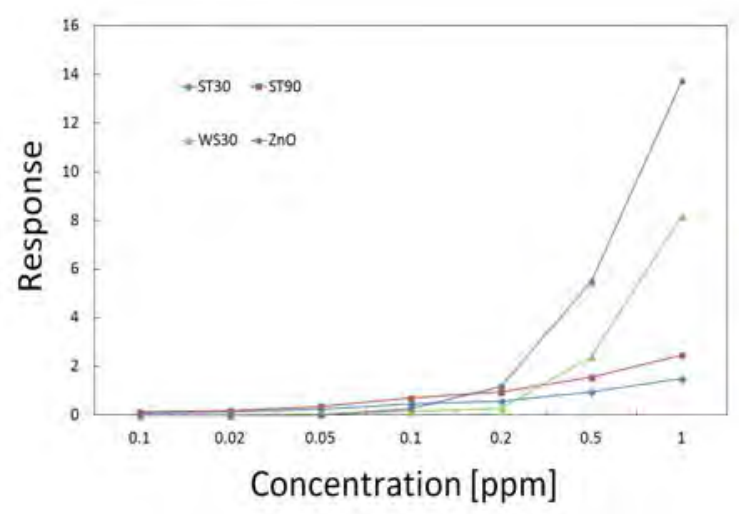

Fig. 3. Responses vs. $\mathrm{H}_{2} \mathrm{~S}$ within 0.01 and $1 \mathrm{ppm}$ dispersed in a dry carrier.

Regarding ethyl-mercaptan, ammonia and hydrogen sulfide, the array encompasses sensors that are very low responsive to at least one gas, while they show significant responses to the others. This feature is a very positive indication for implementation of a highselectivity array. In particular, $\mathrm{ZnO}$ at $450^{\circ} \mathrm{C}$ is 
capable of detecting hydrogen sulfide with little interference by ethyl-mercaptan, ST30 at $600^{\circ} \mathrm{C}$ can selectively detect ammonia, ST90 at $500^{\circ} \mathrm{C}$ is capable to selectively detecting ethylmercaptan. WS30 is sensitive to ethylmercaptan and $\mathrm{H}_{2} \mathrm{~S}$ at low temperatures, while it can selectively detect ammonia at high temperature. Consequently, an array based on $\mathrm{ZnO}, \mathrm{ST} 30$ and ST90 can be employed to detect the gases responsible for malodors in waste storage locations. The sensitivity of $\mathrm{ZnO}$ and WS30, defined as the derivative of the response vs. gas concentration, strongly increases after $0.2 \mathrm{ppm}$ of $\mathrm{H}_{2} \mathrm{~S}$. This is a useful feature since health risks becomes significant at such concentrations. For the other sensors vs. the other gases, the response is quite high to concentrations below the exposure limits.

The response of the sensors was also tested vs. the highest concentration of each gas dispersed in a wet carrier $\left(\mathrm{RH}=23 \%\right.$ at $\left.35^{\circ} \mathrm{C}\right)$. Significant decrease in the response was recorded though it does not invalidate the capability of detection of the target gases (Fig. 4).

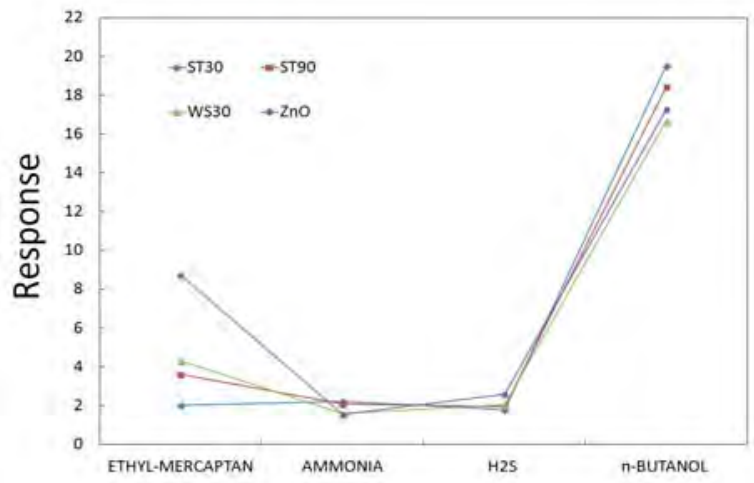

Fig. 4. Responses to $0.5 \mathrm{ppm}$ of ethyl-mercaptan, 30 ppm of n-butanol, $10 \mathrm{ppm}$ of ammonia, 5ppm of acetaldehyde, and $1 \mathrm{ppm}$ of $\mathrm{H}_{2} \mathrm{~S}$ dispersed in a wet carrier.

\section{c. Response to n-butanol}

The most part of molecules which are able to produce odor, are characterized by a very low olfactory threshold, then odor is well sniffed even if the gas concentration in air is negligible. This means that the odor intensity is not proportional to the gas concentration. In fact, due to the synergic and/or inhibiting effects between odorants, the relationships between the odor concentration and the chemical concentrations of the compounds are difficult to realize and reproduce. The odor concentration measurements can be carried out by three methods: analytical determination through mass spectroscopy or marker substances individuations, electronic nose and olfactometry. This work is based on the last technique. In fact olfactometry is currently used worldwide in odor quantification because of it gives more useful information than the other two methods $[14,15]$. A test panel formed by selected and experienced persons, sniffs odorous gas samples conveniently diluited by odorless air on base of determinated relations so that each sample is presented to the panel following a decreasing diluition series. In this way the panel identifies the "odor threshold" and it is possible to digitize a sensation in order to create an odor intensity scale (Odor Units). Relying essentially on human expertise, it is considered a time-consuming and expensive method when used frequently. In this work we needed a reference gas for the odorimetric intensity scale in order to compare the responses obtained with gaseous malodors. Therefore, we chose n-butanol and tested the sensors array with a concentration of $5 \mathrm{ppm}$, which corresponds to a weak odor (about 12 OU - Odor Units) [16]. In the case of n-butanol the temperature test shows a homogeneous behavior for all sensing films (Fig. 5) and the working temperature values obtained are reported in Table 2.

\begin{tabular}{|c|c|}
\hline Sensor & $\begin{array}{c}\text { N-BUTANOL } \\
\mathbf{5 p p m}\left[{ }^{\circ} \mathbf{C}\right]\end{array}$ \\
\hline ST30 & 550 \\
\hline ST90 & 550 \\
\hline WS30 & 600 \\
\hline ZnO & 400 \\
\hline
\end{tabular}

Tab. 2: The optimal working temperature Tbest for n-butanol measurements.

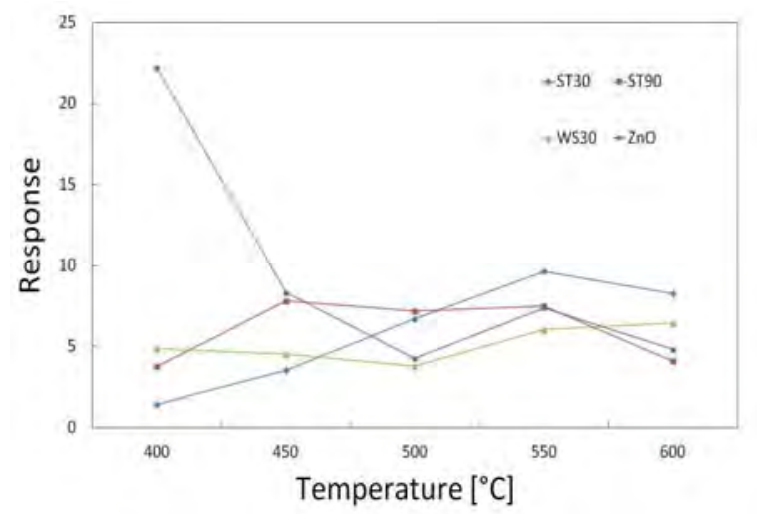

Fig. 5. Response of the set of sensors to $5 \mathrm{ppm}$ of $n$ butanol vs. temperature in dry condition.

Then, once the best temperature for each type of sensor has been fixed, we measured the response to an increasing concentration of $n$ butanol, as highlighted in Fig. 6. 


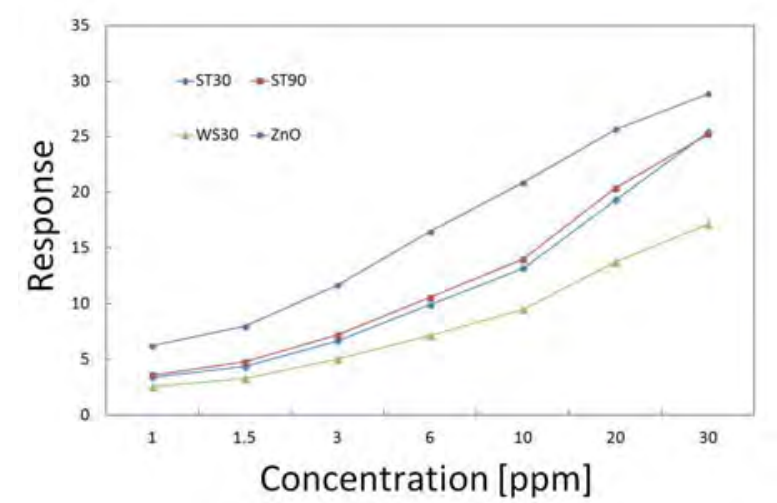

Fig. 6. Responses vs. $n$-butanol within 1 and 30 ppm dispersed in a dry carrier.

Since the sensors were capable of detecting concentrations of $n$-butanol even lower than 1 ppm, which corresponds to about $2 \mathrm{OU}$, one can conclude that sensing units are suitable not only for environmental monitoring but also for odorimetric applications. About this, since the human perception threshold is about $10 \mathrm{OU}$, it can be affirmed that the odorimetric performance of the sensors vs. n-butanol appears to be way better than the human olfact.

\section{d. Response to harmful interfering gases}

The responses of the sensors were also tested vs. $\mathrm{CO}, \mathrm{C}_{6} \mathrm{H}_{6}$ and $\mathrm{NO}_{2}$, since they are harmful interfering gases in zones where waste treatment plants are located. The concentrations were chosen as follows: $10 \mathrm{ppm}$ for $\mathrm{CO}, 2 \mathrm{ppm}$ for $\mathrm{C}_{6} \mathrm{H}_{6}$ and $4 \mathrm{ppm} \mathrm{NO}$, these being concentrations high enough to simulate strong interference from combustion plants near the landfills.

The results are summarized in Figs. 7-9, where the responses of the sensors vs $\mathrm{CO}, \mathrm{C}_{6} \mathrm{H}_{6}$ and $\mathrm{NO}_{2}$ at several working temperatures are reported.

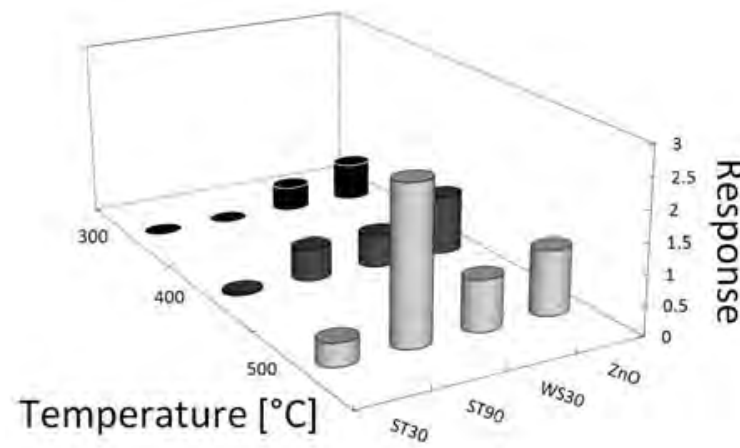

Fig. 7. Responses of the sensors to $10 \mathrm{ppm}$ of CO at three different temperatures.

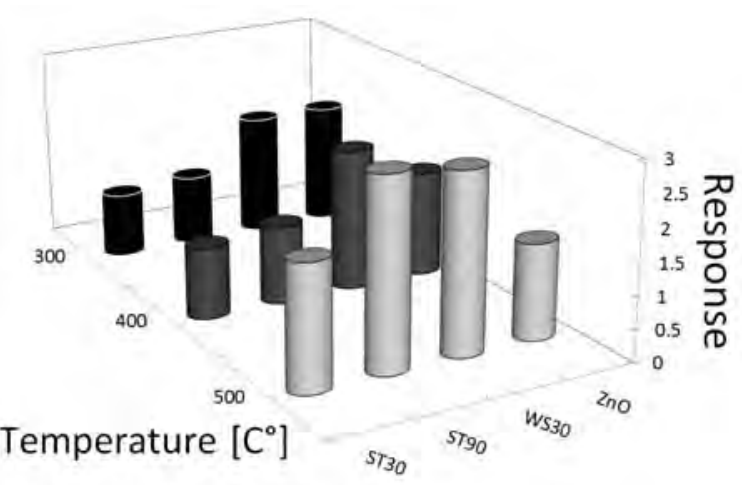

Fig. 8. Responses of the sensors to $2 \mathrm{ppm}$ of $\mathrm{C}_{6} \mathrm{H}_{6}$ at three different temperatures.

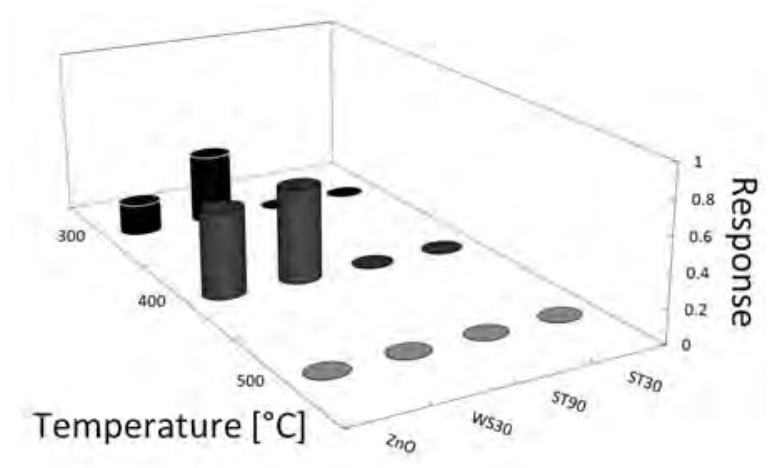

Fig. 9. Responses of the sensors to $4 \mathrm{ppm}$ of $\mathrm{NO}_{2}$ at three different temperatures.

As can be seen, all sensors show very low responses to these relatively high amounts of interfering gases. Indeed, the majority of responses are lower than the unity and in the worst case the response is less than 3 , these latter being values low enough to be considered negligible in comparison with the responses to ethyl-mercaptan, ammonia and hydrogen sulfide. Therefore, the selected array of sensors can be employed in an array capable to selectively detecting the main gaseous malodors in landfills, without the interference of combustion gases that can harmfully affect the measurements.

\section{Conclusions}

The problem of sensing harmful gas pollutants and malodors typical of decomposition of organic substances has been addressed via chemoresistive gas sensors. A set of four sensing materials ( $\mathrm{ZnO}$, two mixed solutions of $\mathrm{Sn}$ and Ti oxides and a mixed solution of $\mathrm{W}$ and Sn oxides) has been tested in dry and wet conditions. It resulted that with a proper choice of the working temperatures the array can sensitively detect the target gases and quantify both the health risk and the odor intensity. The interference of typical gaseous species that can 
be produced in waste treatment plants has been evaluated, and it resulted in a negligible response to $\mathrm{CO}, \mathrm{C}_{6} \mathrm{H}_{6}$ and $\mathrm{NO}_{2}$ by all the sensors.

\section{Acknowledgments}

The results presented are part of the activities carried out by the Laboratory MIST E-R Tecnopolo AMBIMAT of Bologna and the Tecnopolo Terra\&Acqua Tech of Ferrara. This work is financed by the FESR 2007-2013 Operational Program of the Emilia-Romagna Region-Activities I.1.1. B. Fabbri acknowledges financial support by Spinner Regione EmilaRomagna.

\section{References}

[1] V. Guidi, M.C. Carotta, B. Fabbri, S. Gherardi, A. Giberti, C. Malagù, Array of sensors for detection of gaseous malodors in organic decomposition products, Sensors and Actuators B 174 (2012) 349- 354

[2] E. Comini, V. Guidi, M. Ferroni, G. Sberveglieri, Detection of landfill gases by chemoresistive sensors based on titanium, molybdenum, tungsten oxides, IEEE Sensors J. 5 (2005) 4-11

[3] E. Comini, V. Guidi, M. Ferroni, G. Sberveglieri, $\mathrm{TiO}_{2}: \mathrm{Mo}, \mathrm{MoO}_{3}: \mathrm{Ti}, \mathrm{TiO}+\mathrm{WO}_{3}$ and $\mathrm{TiO}: \mathrm{W}$ layer for landfill produced gases sensing, Sensors and Actuators B 100 (2004) 41-46

[4] P.G. Micone, C. Guy, Odour quantification by a sensor array: An application to landfill gas odours from two different municipal waste treatment works, Sensors and Actuators B 120 (2007) 628637

[5] Anne-Claude Romain, Julien Delva, Jacques Nicolas, Complementary approaches to measure environmental odours emitted by landfill areas, Sensors and Actuators B 131 (2008) 18-23

[6] K. Wetchakun, T. Samerjai, N. Tamaekong, C. Liewhiran, C. Siriwong, V. Kruefu, A. Wisitsoraat, A. Tuantranont, S. Phanichphant, Semiconducting metal oxides as sensors for environmentally hazardous gases, Sensors and Actuators B 160 (2011) 580-591

[7] N. Defoer, H. Van Langenhove, Variability and repeatability of olfactometric results of $n$-butanol, pig odour and a synthetic gas mixture, Water Sci. Technol. 4 (2004) 65-73

[8] M.C. Carotta, A. Cervi, V. di Natale, S. Gherardi, A. Giberti, V. Guidi, D. Puzziovio, B. Vendemiati, G. Martinelli, M. Sacerdoti, D. Calestani, A. Zappettini, M. Zha, L. Zanotti, Sensors and $\begin{array}{llllll}\text { Actuators } & \text { B } & 137 & \text { (2009) } & 164-169 .\end{array}$ doi:10.1016/j.snb.2008.11.007

[9] A. Chiorino, G. Ghiotti, F. Prineto, M.C. Carotta, C. Malagù, G. Martinelli, Preparation and characterization of $\mathrm{SnO}_{2}$ and $\mathrm{WO}_{x}-\mathrm{SnO}_{2}$ nanosized powders and thick films for gas sensing, Sens. Actuators B 78 (2001) 89-97
[10] B. Shouli, L. Dianqing, H. Dongmei, L. Ruixian, C. Aifan, C. C. Liu, Preparation, characterization of $\mathrm{WO}_{3}-\mathrm{SnO}_{2}$ nanocomposites and their sensing properties for $\mathrm{NO}_{2}$, Sens. Actuators B 150 (2010) 749-755

[11] M.C. Carotta, S. Gherardi, V. Guidi, C. Malagù, G. Martinelli, B. Vendemiati, M. Sacerdoti, G. Ghiotti, S. Morandi, A. Bismuto, P. Maddalena, A. Setaro, Sensors and Actuators B 130 (2008) 3845. doi:10.1016/j.snb.2007.07.112

[12] M.C. Carotta, A. Cervi, A. Giberti, V. Guidi, C. Malagù, G. Martinelli, D. Puzzovio, Sensors and $\begin{array}{llll}\text { Actuators B } & 133 \quad \text { (2008) 516-520. }\end{array}$ doi:10.1016/j.snb.2008.03.012

[13] M.C. Carotta, A. Cervi, A. Giberti, V. Guidi, C. Malagù, G. Martinelli, D. Puzziovio, Sensors and $\begin{array}{lllll}\text { Actuators } & \text { B } & 136 & \text { (2009) } & \text { 405-409 }\end{array}$ doi:10.1016/j.snb.2008.12.052

[14] ASTM International, E679-04: Standard Practice for Determination of Odor and Taste Thresholds By a Forced-Choice Ascending Concentration Series Method of Limits, USA, 2005

[15] European Committee for Standardization, EN 13725: Air Quality-Determination of Odour Concentration by Dynamic Olfactometry, 2002

[16] J. C. Segura, J. J. R. Feddes, Relationship Between Odour Intensity and Concentration of nButanol, CSAE/SCGR 2005 Meeting Winnipeg, Manitoba June 26 - 29, 2005, Paper No. 05-020 